\title{
Aggressive Breast Cancer during Pregnancy with a Rare Form of Metastasis in the Maternal Placenta
}

\section{Aggressives Mammakarzinom in der Schwangerschaft mit einer seltenen Form der Metastasierung in die mütterliche Plazenta}

Authors

Affiliations
G. Vetter ${ }^{1}$, F. Zimmermann ${ }^{2}$, E. Bruder ${ }^{3}$, S. Schulzke ${ }^{5}$, I. Hösli ${ }^{1}$, M. Vetter ${ }^{4}$

${ }^{1}$ Klinik für Geburtshilfe und Perinatalmedizin, Universitätsspital Basel, Schweiz

${ }^{2}$ Klinik für Radioonkologie, Universitätsspital Basel, Schweiz

${ }^{3}$ Institut für Pathologie, Universitätsspital Basel, Schweiz

${ }^{4}$ Klinik für Medizinische Onkologie, Universitätsspital Basel, Schweiz

${ }^{5}$ Universitäts-Kinderspital beider Basel (UKBB), Universitätsspital Basel, Schweiz
Key words

- breast cancer

- pregnancy

- placenta metastasis

Schlüsselwörter

- Mammakarzinom

- Schwangerschaft

- Plazentametastase

Deutschsprachige Zusatzinformationen online abrufbar unter: www.thieme-connect.de/ ejournals/toc/gebfra $\begin{array}{ll}\text { received } & 23.10 .2013 \\ \text { revised } & 22.12 .2013 \\ \text { accepted } & 10.1 .2014\end{array}$

Bibliography

Dol http://dx.doi.org/ 10.1055/s-0034-1368181

Geburtsh Frauenheilk 2014; 74: 579-582 @ Georg Thieme Verlag KG Stuttgart · New York ISSN 0016-5751

\section{Correspondence}

Dr. med. Grit Vetter

Klinik für Geburtshilfe und Perinatalmedizin

Universitätsspital Basel

Spitalstrasse 21

4031 Basel

Switzerland

grit.vetter@usb.ch

\section{Abstract}

$\nabla$

Breast cancer is the second most common cancer diagnosed during pregnancy. Here we describe a 29-year-old patient with a recurrence of breast cancer with simultaneous brain, pulmonary and placenta metastasis. An overview of the literature on placenta metastases is provided together with a report on the interdisciplinary medical management.

\section{Introduction}

$\nabla$

Breast cancer is diagnosed in one in 3000 pregnancies, which corresponds to $10 \%$ of diagnosed cases of breast cancer in women under 40 [1]. This makes it the second most common form of malignant cancer during pregnancy, behind cervical cancer.

In the past it was assumed that breast cancer associated with pregnancy had a worse prognosis than a cancer occurring outside of pregnancy [2] It is frequently present in an advanced stage with larger tumours and more extensive lymph node involvement. However, in matched pair analyses according to age and stage, pregnancy was able to be largely ruled out as a prognosis factor. It could also be shown that the occurrence of pregnancy after treated breast cancer did not result in an increased risk of recurrence [3]. There is some evidence that the frequency of distant metastasis decreases in pregnancy [4]. We describe the case of a patient who fell pregnant 55 months after an initial diagnosis of breast cancer and for whom brain, pulmonary and placenta metastasis first became evident during the 26th WOP.

\section{Zusammenfassung \\ $\nabla$}

Das Mammakarzinom ist die zweithäufigste Krebserkrankung, die während der Schwangerschaft diagnostiziert wird. Wir beschreiben hier eine 29-jährige Patientin, die ein Rezidiv eines Mammakarzinoms mit einer synchronen Hirn-, Lungen- und Plazentametastasierung aufweist. Es wird ein Literaturüberblick über Plazentametastasen gegeben sowie über das interdisziplinäre medizinische Management berichtet.

\section{Case History}

The 29-year-old gravida I patient was admitted due to dizziness in the $25+4$ WOP. Fifty-five months before, the patient had been diagnosed with invasive ductal breast cancer of the right breast (stage: pT2pN0 [0/18LK] cM0 G3 L1 V0 R0, ER/PR neg., HER2-new neg., Ki-67: 70\%). She received breast-conserving treatment with additional local resection and axillary lymph nodectomy. Adjuvant, systemic chemotherapy took place with 3 cycles of FEC (5FU, epirubicin, cylophosphamide) and 3 cycles of docetaxel. This was followed by percutaneous radiotherapy for the breast ( $50 \mathrm{~Gy}$ across the whole breast area, $66 \mathrm{~Gy}$ in the area of the tumour bed, $5 \times 2.0 \mathrm{~Gy}$ per week). The patient was in regular aftercare with her gynaecologist.

At the end of 2012 she fell pregnant spontaneously and the pregnancy progressed smoothly until the 26th WOP. When dizziness followed and dyspraxia of the right hand was identified in the $25+4$ WOP, a brain MRI was performed (multiplanar, T1 \pm Gd, T2 weighting), which showed 7 brain metastases. The largest metastasis was cerebellar (35 mm diameter) and led to a compression of the brainstem, an extensive shift of the 4th ventricular and the start of an asymmetry of the cerebrospinal fluid system ( Fig.1a). She 

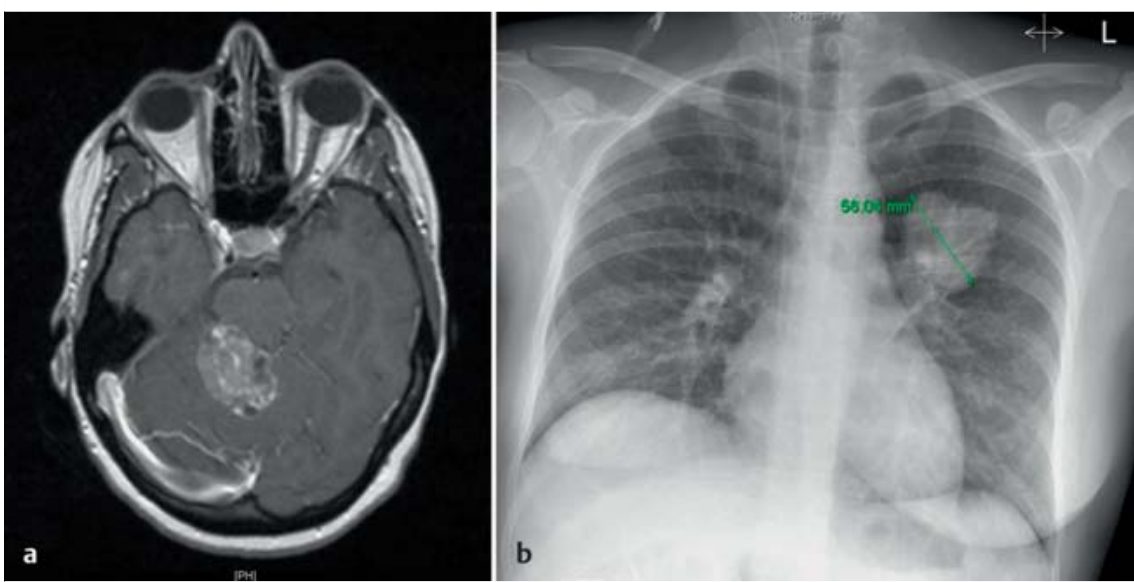

Fig. $1 \mathbf{a}$ and $\mathbf{b}$

a Brain MRI: The T1 weighting with KM shows a

large brainstem-compressing metastasis;

b Thorax $\mathrm{x}$-ray shows a pulmonary metastasis

$56 \mathrm{~mm}$ in diameter.
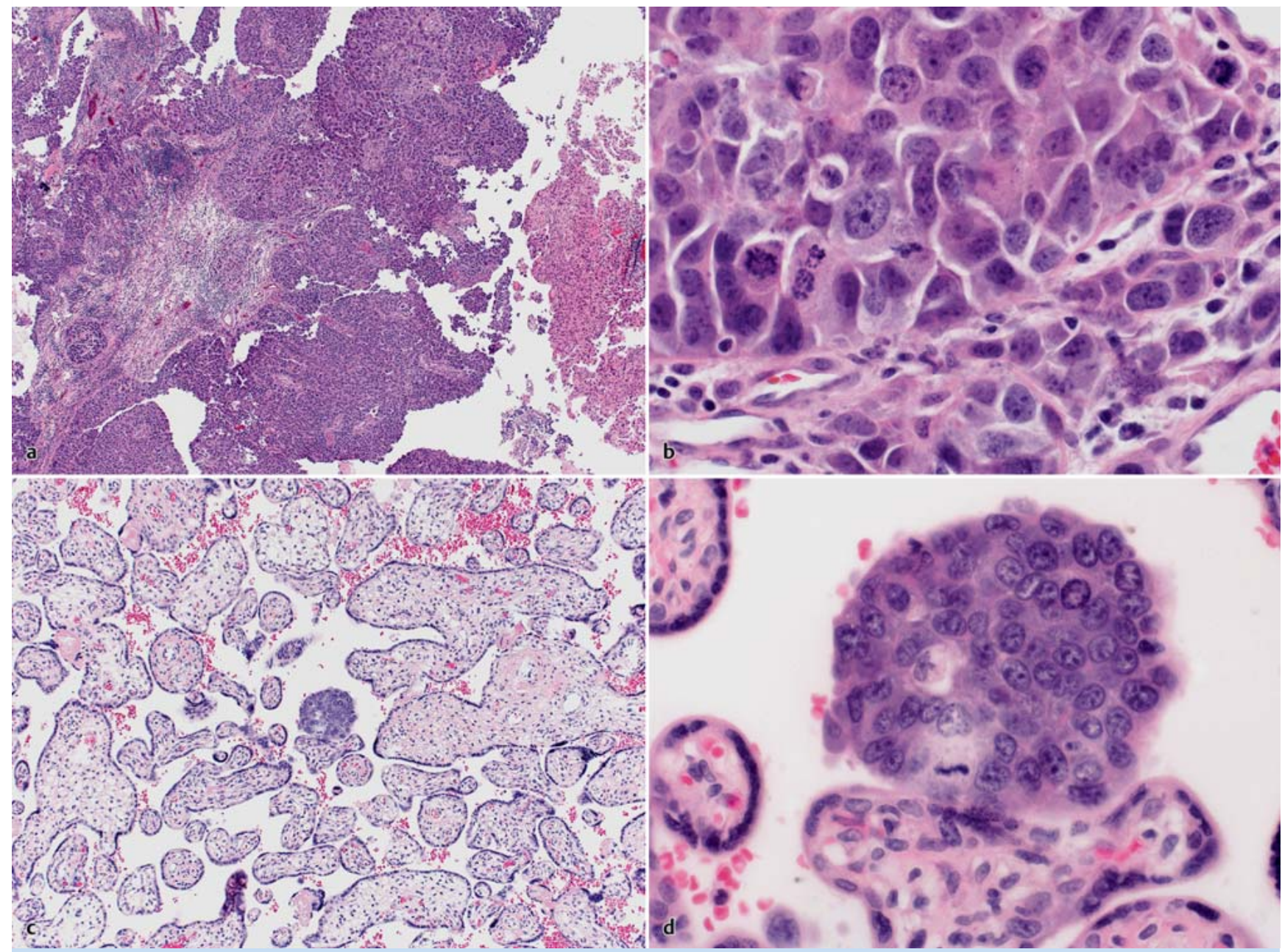

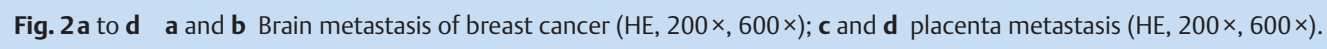

was resected for quick relief and diagnosis. The histology shows a metastasis of the known breast cancer (ER/PgR negative, HER2 IHC positive) ( Fig. 2 a and b). Further staging examinations resulted in inconspicuous sonographic findings in the abdomen, but a $56 \mathrm{~mm}$ mass in projection on the centre left ( Fig. $\mathbf{1}$ b). Due to a lack of pulmonary symptoms and for reasons of radiation protection, an X-ray was only performed in one level (p.-a. recording).
Overall, the patient recovered well from the operation. There was a complete recovery of the neurological deficits.

As part of a multidisciplinary approach it was decided, together with the patient and her relatives, not to perform any further oncological treatment for the time being, but to monitor the progress closely and continue the pregnancy to the 35th WOP. A prophylactic lung maturation of the child under tocolysis with an average of $2 \times 12 \mathrm{mg}$ celestone was performed as a preventive 
measure prior to the neurosurgical intervention. The 34th WOP was selected, as at this time the foetal mortality risk is below $1 \%$ and the morbidity risk (predominantly respiratory adaptation disorders) is about $12 \%$ [5].

The brain metastases were considered to be prognostically significant so that, besides the weekly clinical processes, a further magnetic resonance imaging of the brain took place after 3 weeks. This MRI, performed in the 30th WOP showed a progression of the brain metastases. The lung metastasis described above had also grown by $5 \mathrm{~mm}$, so that a decision was made for delivery by caesarean section in the $30+3$ WOP, deviating from the original plan. At this time, the likelihood of a foetal respiratory disorder was about $60 \%$ and mortality about $5 \%$.

The caesarean section was performed without any problems, and a premature girl, well developed for her age, was delivered with a weight of $1580 \mathrm{~g}$, and was moved to the neonatal intensive care unit of the University Children's Hospital due to the prematurity and a primary respiratory distress syndrome (RDS).

Here, a delayed primary adaptation with an Apgar of 6/9/9 was identified with an inconspicuous $\mathrm{NSpH}$ venous of $7.47(\mathrm{NSpH}$ arterially collapsed). Nasal positive airway pressure (CPAP) had already commenced for the primary RDS as part of the initial treatment. On the first day of life there was an acute respiratory deterioration of the situation with insufficient oxygenation and hypercapnia due to a tension pneumothorax on the right side, which was able to be relieved immediately with joint aspiration. This was followed by conventional ventilation over 3 days with subsequent uncomplicated progress. A temporary feeding weakness due to prematurity also occurred, as well as the treatment of hyperbilirubinaemia, hypoglycaemia and neonatal anaemia all resulting from prematurity. However, the child's progress was satisfactory overall and it was discharged on the 54th day of life $(37+6$ WOP $)$.

The histological reprocessing of the received placenta showed evidence of a small intraparenchymal metastasis in the intervillous space without any suggestion of involvement of the foetal villous stroma or the foetal vascular circulation ( $\bullet$ Fig. $2 \mathrm{c}$ and $\mathbf{d}$ ). A palliative radiotherapy of the brain took place immediately after discharge for long-term intracerebral tumour control, and systemic palliative chemotherapy with docetaxel, trastuzumab and pertuzumab was introduced. After the conclusion of the cerebral radiotherapy and 6 cycles of chemotherapy, the MRI scan of the brain showed a partial tumour remission and the CT thorax/abdomen/pelvis showed a stable tumour situation.

Consolidating radiotherapy of the pulmonary metastasis was planned for three weeks after conclusion. A new pulmonary metastasis had appeared in the lower left lobe in the thorax planning CT. Both pulmonary metastases were subsequently radiated. The trastuzumab/pertuzumab maintenance therapy was initially continued. Further progression with new bone and soft part metastases was identified six weeks after the conclusion of the radiotherapy. A treatment with T-DM1 was introduced, which is currently being tolerated well by the patient.

\section{Discussion}

$\nabla$

The occurrence of cancer during pregnancy is rare; however, it is likely that there is an increased risk of cancer during pregnancy with increasing age of the mother at the birth of the first child [6]. In particular, case descriptions for metastasised breast cancers are very rare. The risk of relapse for triple negative breast cancer falls considerably after 5 years, generally to below the risk of relapse of hormone-receptor positive breast cancer. The diagnostics and treatment of cancers at the limit of viability of the foetus are especially challenging as well as conflictual, as no large-scale studies exist and treatment for the mother should not be inadequate while the risk to the foetus should not be unnecessarily acute or chronic.

After removing the symptomatic intracranial brain metastasis we decided, together with the patient, on a closely monitored weekly follow-up with additional interventions if the disease progressed. Radiotherapy of the brain and the start of palliative chemotherapy with docetaxel, trastuzumab and pertuzumab were planned to be commenced promptly after delivery of the child.

The background for the decision and the decision against immediate radiotherapy was, first of all, the successful surgical removal of the single critical brain metastasis. All other metastases were asymptomatic, less than $7 \mathrm{~mm}$ in size and had no significant concomitant oedema. On the other hand, the indication for radiotherapy during pregnancy is generally very cautious, especially during the organogeny. While during blastogenesis it can be assumed that any impact of radiation either heals without any problems or can result in abortion, the malformation of organs may especially occur during embryogenesis (3-8 weeks) and more rarely during the following fetogenesis. The risk falls considerably in the last 3 months of pregnancy. After organogenesis had concluded for our patient's child, the key aspect of the decision against immediate radiotherapy was a possible rise in developmental disorders and the subsequent appearance of malignant tumours in the child, even if these risks are very low. It is assumed that the foetal CNS is particularly sensitive to radiation 8-25 weeks after conception. This may result in mental retardation. For a foetus between 16-25 WOP, only a dose below $0.25 \mathrm{~Gy}$ is assumed to be relatively safe $[7,8]$. However, our focus was on the increased risk to the child of suffering from a malignant growth later in life, for which a dose-response relationship can be assumed, but for which no lower limit dose under which the problem could no longer occur exists. The distance of the radiotherapy target area from the child, the selection of the type of radiation and the radiation technology are decisive for the foetal dose. The cumulative radiation doses in the pelvic area are very low for radiotherapy of the brain. According to our measurements on phantoms and in computer planning, the child would only have been exposed to a very low cumulative radiation dose ( $<0.5 \%$ of the dose). As a result, radiotherapy of the brain during pregnancy can be viewed as safe for the organic and functional development of a foetus. However, a risk does remain with regard to a malignancy induction, especially during childhood and youth (e.g. leukaemia), without the availability of any clear data. In our case, the wait and see approach with close observation did not risk the prognosis of the patient as, in the case of freedom from symptoms, there is no convincing data for a survival benefit of palliative oncology treatment that is started a few weeks earlier in this situation.

Trastuzumab is a category D medication in pregnancy, and its administration is restricted to individual cases $[9,10]$. As a result, no recommendation to administer the medication can be provided. The occurrence of oligo/anhydramnios is described in the 2nd trimester. Its administration should therefore only take place under close observation of the amniotic fluid [11]. The taxane docetaxel also belongs to the category $\mathrm{D}$ medications during pregnancy. Some studies show that its administration has no adverse effect 
on the mother and child, provided that it is administered in the 2 nd or 3rd trimester $[12,13]$. The literature has no information on the administration of pertuzumab during pregnancy.

The first follow-up MRI scan of the brain 4 weeks after the craniotomy showed a progression of the existing brain metastases, such that the caesarean section was performed in the 31st WOP, given matured lungs and a well-developed child, and radiotherapy as well as chemotherapy was introduced.

In any case, the time of delivery and the decision on when to start the treatment should be considered carefully and discussed in a multidisciplinary exchange involving the affected couple. In particular, the risk to the child with regard to prematurity and the benefits of adequate early treatment for the mother must be considered. In our case, despite successful overall progress, the child required intensive neonatal care with treatment of a tension pneumothorax as well as anaemia, hypoglycaemia and hyperbilirubinaemia due to prematurity.

Our patient displayed a rare case of placental micrometastasis of the known breast cancer ( $\mathbf{O}$ Fig. $\mathbf{2} \mathbf{c}$ and $\mathbf{d}$ ). A case series from the Journal of Clinical Oncology from 2003 displays a compilation of 87 cases with placental or foetal metastasis between 1866 and 2003 [14]. The most frequent occurrence is in the case of melanoma, breast cancer, lung cancer, leukaemia and lymphoma. The data also shows that a maternal-foetal transmission of the tumour cells occurs only in very rare cases. Evidence of these kinds of metastases, according to the individual cases provided, is bound up with a poor prognosis for the mother. This is likely to be explained by the aggressiveness of the tumour. The foetus is generally free of any tumours, if the metastasis is limited to the intervillous space, as is the case with our patient [15]. However, the prognosis for the child in the case of foetal metastasis is generally described as poor [16].

In theory, the placenta is an ideal environment for tumour cells due to the large surface and pronounced blood flow [17]. Breast cancer during pregnancy is frequently described and studied [18]. However, only a few cases of placenta metastasis have been described in the global literature [14], so the effect on the child as well as on the mother cannot be reliably forecast. It is likely that the placental barrier protects the child's circulation. The extent to which the tumour cells are able to pass through the placental barrier is not reliably explained. Whether the same laws of invasiveness apply here has also not been studied.

In a cell culture model with human first trimester placenta tissue, Tartakover-Matalon et al. showed that the breast cancer cell lines MCF7 and T47D were eliminated and prevented during the placenta invasion [19]. The number of cells shrank by about 45 and $48 \%$ respectively, especially near the explanted placenta tissue. Furthermore, an increased activity of Matrix metalloproteinases and the placenta soluble factor was demonstrated as well as a reduced expression of the oestrogen receptors in the tumour cells. However, whether this model can be transferred to an in-vi- tro model or even to humans remains unclear. This may be an interesting topic to pursue for further treatment approaches.

\section{Conflict of Interest}

None.

\section{Literature}

1 Barnes DM, Newman LA. Pregnancy-associated breast cancer: a literature review. Surg Clin North Am 2007; 87: 417-430

2 Guinee VF, Olsson H, Möller T et al. Effect of pregnancy on prognosis for young women with breast cancer. Lancet 1994; 343: 1587-1589

3 Upponi SS, Ahmad F, Whitaker IS et al. Pregnancy after breast cancer. Eur J Cancer 2003; 39: 736-741

4 von Schoultz E, Johansson $H$, Wilking $N$ et al. Influence of prior and subsequent pregnancy on breast cancer prognosis. J Clin Oncol 1995; 13: 430-434

5 Mercer BM. Preterm premature rupture of the membranes. Obstet Gynecol 2003; 101: 178-193

6 Han SN, Kesic VI, Van Calsteren Ket al.; ESGO 'Cancer in Pregnancy’ Task Force. Cancer in pregnancy: a survey of current clinical practice. Eur J Obstet Gynecol Reprod Biol 2013; 167: 18-23

$7 \mathrm{Kal} \mathrm{HB}$, Struikmans $\mathrm{H}$. Radiotherapy during pregnancy: fact and fiction. Lancet Oncol 2005; 6: 328-333

8 Nakagawa K, Aoki Y, Kusama T et al. Radiotherapy during pregnancy: effects on fetuses and neonates. Clin Ther 1997; 19: 770-777

9 Bader AA, Schlembach D, Tamussino KF et al. Anhydramnios associated with administration of trastuzumab and paclitaxel for metastatic breast cancer during pregnancy. Lancet Oncol 2007; 8: 79-81

10 Shrim A, Garcia-Bournissen F, Maxwell C et al. Trastuzumab treatment for breast cancer during pregnancy. Can Fam Physician 2008; 54: 3132

11 Mandrawa CL, Stewart J, Fabinyi GC et al. A case study of trastuzumab treatment for metastatic breast cancer in pregnancy: fetal risks and management of cerebral metastases. Aust N Z J Obstet Gynaecol 2011; 51: 372-376

12 Monteiro DL, Trajano AJ, Menezes DC et al. [Breast cancer during pregnancy and chemotherapy: a systematic review]. Rev Assoc Med Bras 2013; 59: 174-180

13 Cardonick E, Bhat A, Gilmandyar D et al. Maternal and fetal outcomes of taxane chemotherapy in breast and ovarian cancer during pregnancy: case series and review of the literature. Ann Oncol 2012; 23: 3016 3023

14 Alexander A, Samlowski WE, Grossman D et al. Metastatic melanoma in pregnancy: risk of transplacental metastases in the infant. J Clin Oncol 2003; 21: 2179-2186

15 Ben Brahim E, Mrad K, Driss M et al. Placental metastasis of breast cancer. Gynecol Obstet Fertil 2001; 29: 545-548

16 Catlin EA, Roberts jr. JD, Erana $R$ et al. Transplacental transmission of natural-killer-cell lymphoma. N Engl J Med 1999; 341: 85-91

17 Jackisch C, Louwen F, Schwenkhagen A et al. Lung cancer during pregnancy involving the products of conception and a review of the literature. Arch Gynecol Obstet 2003; 268: 69-77

18 Loibl S, Han SN, von Minckwitz G et al. Treatment of breast cancer during pregnancy: an observational study. Lancet Oncol 2012; 13: 887896

19 Tartakover-Matalon S, Mizrahi A, Epstein G et al. Breast cancer characteristics are modified by first trimester human placenta: in vitro coculture study. Hum Reprod 2010; 25: 2441-2454 